\title{
Shared Services in Irish Local Government
}

\author{
Mark Scannell ${ }^{1}$ and Frank Bannister ${ }^{2}$ \\ ${ }^{1}$ Local Government Management Agency, Dublin, Ireland \\ Mark. Scannell@lgma.ie \\ ${ }^{2}$ Trinity College, Dublin, Ireland \\ Frank.Bannister@tcd.ie
}

\begin{abstract}
This paper investigates the demand for ICT shared services in Irish local government, why has the take-up to date been so limited and what the barriers to adoption are historically and are today. The research shows that there is an apparent large demand for ICT shared services from all local authorities, but that in practice take-up is low and there is a strong preference for local solutions over national offerings. A number of barriers to adoption are identified and discussed.
\end{abstract}

Keywords: ICT, shared services, local government, e-government, governance.

\section{$1 \quad$ Introduction}

\subsection{Research Questions}

For a variety of reasons, e-government has given rise to a renewed interest in shared services in government ICT. The most recent cause of this has been the emergence of cloud computing, but pressures to save costs have also been a significant factor [21]. In Ireland, the use of shared services in local government goes back nearly three decades and its chequered history over this period offers a particular opportunity to study this phenomenon. The low take-up of shared services Irish local government is surprising. Research suggests that shared services are a logical way of organizing ICT for non competing entities delivering similar services. Ulbrich [27; 28] describes wholly owned systems as an "unaffordable luxury". A survey by AT Kearney in 2003 [1] found that popular candidates for shared services include human resources management and ICT.

The lack of take-up is even more puzzling given that local authorities are a particularly good fit for shared ICT services. There are many variations of shared service model. One is where a number of non-competing organisations provide broadly the same range of services to different customers, clients or constituencies. Examples of such groups in the public sector include hospitals, parts of the education system and local government. Local governments typically provide an almost identical range of services to different geographical areas. Such services include maintenance of roads, provision of water and sewage services, social housing, planning, emergency services and refuse collection. A computer system designed for one local authority (LA) 
should in theory fit all LAs or require only minor local tailoring to do so. Consequently, when it comes to the provision of ICT services, there is a number of strong arguments for collaborative development and sharing including economies of scale, sharing of scarce resources and pooling of expertise. Despite this, in Ireland, instead of sharing services many local authorities choose to ignore centrally developed systems and instead develop their own equivalents. Two obvious questions are why is this so and what, if anything, can be done to change this position? This research therefore set out to answer the following four questions:

- What is the potential demand for ICT shared services in Irish local authorities?

- What is the level of take-up of shared services in Irish local government?

- What are the barriers to the adoption of ICT shared services in Irish LAs?

- What might increase the level of use of shared services by LAs in Ireland?

\subsection{A Brief Background}

The main Irish local authorities comprise 29 county councils and five city councils A shared service provider, the Local Government Computer Services Board (LGCSB), was established in 1973 with a mission to provide computer services, particularly software application development, to all LAs in Ireland. While a range of services continue to be shared, the success of the LGCSB (now part of the Local Government Management Agency or LGMA) has not been what was hoped.

\section{$2 \quad$ Literature Review}

\subsection{Defining Shared Services}

The concept of shared services in local government goes back to the earliest years of computing. In 1961 the United States Federal Advisory Committee on Intergovernmental Relations (cited in [24]) defined the term shared services as:

"Intergovernmental cooperation at the local level either by formal written contracts or by informal verbal agreements which often provides a workable method of meeting particular problems."

Shared services are often considered a form of outsourcing [13]. Corradini [8] endorses the view of the shared services centre as an internal function. Within these conceptualisations there are several variations. For example, while the shared services might be provided by an internal or separate, but wholly owned, shared services provider (SSP), the SSP may in turn outsource some specific services (such as the provision of $\mathrm{Wi}-\mathrm{Fi}$ ) to one or more third parties (figure 1). 


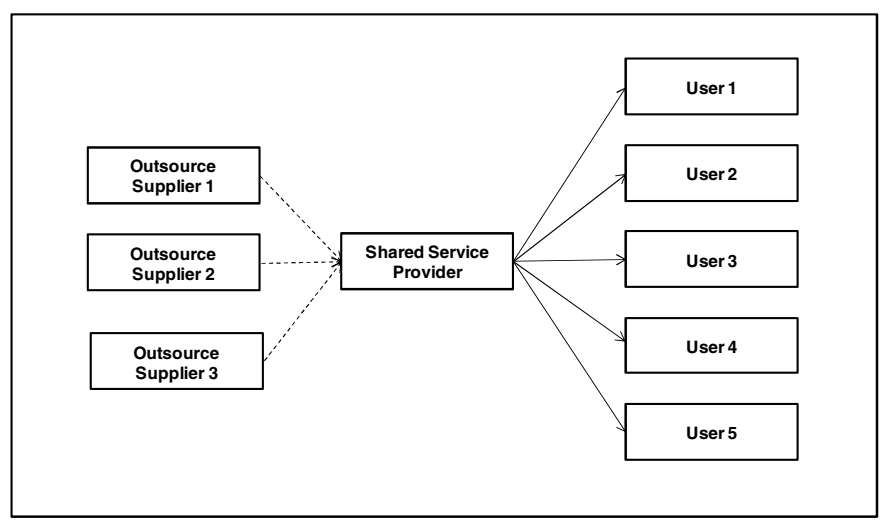

Fig. 1. Single owned provider shared services model (with optional outsourcing)

Tompkinson [26] describes shared services in local government as the shared provision by more than one local authority of a specified service in which service aims and objectives are mutually shared and for which local people are the end users. McWilliams [18] further differentiates between centralisation of ICT and shared services. Centralisation, he states, is about standardising services whereas shared services are customised for individual customer sets. Thus a shared service may be provided by a single internal entity or may be in the form of a network with different individual LAs providing a specific service or set of services.

These are only two of several possibilities. There are many other definitions, see, for example [4], [15], [16], [20]. The definitive characteristic of an ICT shared service is that the users get their ICT services (applications, networks, etc.) from the SSP. For the purposes of this paper shared services will be defined as the sharing of ICT infrastructure including hardware, software, communications and support between two or more local authorities in a centrally hosted environment whether that host is real or virtual, single or multiple hosted. It is accepted that there are other possible definitions, but a more detailed discussion of these is beyond the scope of this paper.

\subsection{Governance}

An important aspect of this research is the governance of shared services. Bannister [2] argues that the mere mention of shared services can result in an outbreak of a power struggle and an accentuated desire for independence based on fear about, inter alia, excessive central control. This problem became evident Ireland in an (unpublished) study carried out by the Institute of Public Administration in Ireland (IPA) in 2004 into the financing of shared ICT services in Irish local government. Power is a major factor in shared service acceptance, though as Ren and Wagenaar [23] point out there are several other reasons for the resistance to adoption of shared services. These objections range from the problems of one-size-fits-all to security risks, the loss of influence over implementation costs and problems with proposed timelines, project plans and local priorities. In this context, the decision making structure within the LGMA itself is a significant factor. This is discussed briefly below. 
For these reasons Weill and Ross [29] argue that for the successful implementation of a shared service solution there must be strong ICT governance. By governance they mean that the processes by which organizations align ICT actions with their performance goals and assign accountability for those actions and their outcomes. To be effective, ICT governance must be actively designed and not the result of isolated mechanisms (such as steering committees, offices of ICT architecture, service level agreements, etc.) implemented at different times to address the challenges of the moment. Good IT governance is essential to overcome barriers to the adoption of a shared services solution. Janssen and Wagenaar [14] discuss the frustration that can occur at user level and the potential for alienation between shared service providers and local users. If this is to be avoided there have to be clear responsibilities and structures. Strong communication, both formal and informal, is important to ensure that this kind of difficulty does not arise. To avoid the types of problem identified by Bannister [2] and Ren and Wagenaar [23], a shared service requires a carefully executed strategy, the re-organisation and redesign of activities and roles, the standardisation of processes, applications and the underlying architecture and the management of the transformation involved by the engagement of all stakeholders [17]. Colman $[6 ; 7]$ suggests that there is a necessity for strong "strategic" management and a good eye for what areas would benefit most from streamlining and consolidation and argues that the quality of the service level agreement (SLA) is critical to success. He argues that a SLA needs what he calls two way accountability, i.e. customers must also be accountable to service providers for their behaviour. Customers of an SSP must be able to feel in control [11], but providers must be respected.

Finally a critical component of good governance is a clear perception of all of the stakeholders. Mitchell et al [19] suggest that power, legitimacy and urgency are attributes that can be used to identify stakeholders. Janssen [12] concurs, noting that stakeholder management is essential to successful shared services.

\subsection{Cost Reduction}

While there are many benefits of shared services, in practice shared services are often driven by pressures to reduce costs. David [9] suggests that centralising business processes can cut costs by between $25 \%$ and $30 \%$. Centralising using a shared service eliminates duplication and can thus reduce costs even further. In Ireland, as elsewhere in the world's public sectors, there is constant pressure to produce more with less.

Smith et al [25] argue that one of the problems in shared services models is cost containment and that such models tend to fail unless there is a demonstrated reduction in cost. Sometimes savings will only become visible over a five to seven year period which is a long time in government thinking. A further contentious issue is the question of how the costs of shared services are to be spread amongst users. LAs resent having to pay for services that they do not use even if they could use them, but choose not to. They feel pressured to use what they regard as an inferior service simply because they are paying for it, something which can become a further source of friction. Nonetheless, shared services as a source of savings are firmly on government agendas (for example in the UK [22]). 
This has only been a brief review of the literature, but a number of key points can be drawn from it. First, there are several conceptualisations of shared services. Second, a key problem in shared services take-up is perceived loss of power and control, but there are several other barriers to take-up. Third, while cost savings are often a primary driver of shared services, often driving out other reasons for implementing such a system, in practice cost savings may be hard to achieve in the short term which can lead to political problems if other benefits have not been part of the business case. Finally, as in so much in information systems, good communication and stakeholder identification and management are critical to success.

\section{$3 \quad$ Research Methodology}

This research was carried out in the spring and summer of 2010. A mixed methods approach using a questionnaire and a small number of extended semi-structured interviews was used. The survey instrument was divided into four sections. The first section collected background/demographic information such as experience, staffing levels and size of budget. The second section asked for factual information about current and potential shared services. The third section sought attitudes and opinions about shared ICT services. In the fourth section respondents were asked about perceived barriers to the adoption of shared services. The instrument included a variety of question types, some using Likert scales and others which were open and which invited free-form comment. The first version of the survey was discussed and modified a number of times before being pilot tested using a number of senior managers in the LGMA. After feedback had been received from them the survey was redesigned and then checked by an expert in survey design. Because of the small number of local authorities, rather than sampling, a census was used. The questionnaire was sent to the Heads of Information Systems (HIS) in each of the 34 local authorities in June 2010. After following up the initial request a total of 23 responses were received.

Following the survey semi structured interviews were held with five senior managers in Irish local government. Three of these were County Managers (i.e. the chief executives in the relevant LAs); the other two people interviewed were senior executives in the LGMA. Each interview took between one and two hours and was undertaken at the interviewee's place of work. While the results from the survey were used in guiding the questions in the interviews, the findings of the survey were not given to the interviewees in advance. In preparation for the interviews, a detailed desk study of the interviewee's organisation and that person's role within that organization was undertaken. Detailed notes were taken and these were written up immediately the interview and checked with the interviewees for accuracy.

\section{$4 \quad$ Findings}

\subsection{Survey}

A feature of the HIS group is that the majority of them have been in their roles a long time. Forty percent have been in their current role for over 10 years and a small 
number have been in their job for over 20 years. The views expressed were therefore mostly those of people with long experience of shared service in Irish LAs. Of the 23 LAs that responded to the survey, 22 reported that their LA either currently participated in at least one shared service or had done so in the past. Table 1 shows the breakdown of shared service currently offered by the LGMA and the number of users of each.

Table 1. Usage levels of shared applications

\begin{tabular}{|l|c|l|c|}
\hline System & No. & System & No. \\
\hline CORE Human Resource (HR) & 16 & Finance & 7 \\
\hline Web Filtering Software & 14 & Road Management Software & 7 \\
\hline Payroll & 14 & Web Filtering Software & 6 \\
\hline Geographical Information Sys. & 12 & Backup Software & 6 \\
\hline Website & 11 & Telecommunications & 6 \\
\hline Higher Education Grants & 10 & Environmental System Complaints & 5 \\
\hline Planning System (iPlan) & 9 & Project Management Systems & 5 \\
\hline Anti Virus Software & 9 & Enforcements & 4 \\
\hline Home or Housing System & 8 & Time Management system & 4 \\
\hline Planning Enquiries & 8 & Email System & 4 \\
\hline Register of Electors & 8 & Water Services Systems & 4 \\
\hline Email Filtering Software & 8 & Fire Station Systems & 3 \\
\hline Procurement & 8 & Road Design Applications & 3 \\
\hline Library & 7 & Tracking Systems & 2 \\
\hline Document Management Sys. & 7 & Compulsory Purchase Order & 2 \\
\hline Library Systems & 7 & & \\
\hline
\end{tabular}

The percentage rate of take-up can be computed as follows:

$\frac{\text { Number of Shared Service Uses x } 100}{\text { Number of LAs x Number of Shared Services Available }}=\frac{22400}{23 \times 31}=31 \%$

which is a low success rate for a service that has been available for nearly four decades. Table 2 shows the responses to the question what services the HISs would consider sharing:

A comparison of both tables shows that, while there is considerable overlap, there are inconsistencies in the responses. For example 18 respondents said that they felt that payroll was a potential shared service. However while this has long been an available service, only 14 of the LAs avail of it. On the opposite side, web filtering software is used by 14 LAs, but only seen as a potentially useful service by three LAs.

The HISs were then asked what services they perceived as primary candidates for shared services. The results are shown in figure 3 . While e-mail was the dominant choice, what is noteworthy is the number of respondents who did not select any service suggesting that they did not see shared services as adding any value. 
Table 2. Shared applications that users would consider adopting

\begin{tabular}{|l|c|l|c|}
\hline System & No. & System & No. \\
\hline Payroll & 18 & Telecommunications & 7 \\
\hline GIS systems & 18 & Enforcements & 7 \\
\hline Register of Electors & 17 & Time Management system & 7 \\
\hline HR & 14 & Website & 6 \\
\hline HEGS & 14 & Compulsory Purchase Order & 6 \\
\hline Email System & 12 & Road Management Software & 5 \\
\hline iPlan & 11 & Environmental System Complaints & 5 \\
\hline Anti Virus Software & 10 & Email Filtering Software & 4 \\
\hline Procurement & 10 & Road Design Applications & 4 \\
\hline Finance & 10 & Web Filtering Software & 3 \\
\hline Water Services Systems & 10 & Document Management System & 3 \\
\hline Planning Enquiries & 9 & Web Filtering Software & 3 \\
\hline Home or Housing System & 8 & Project Management Systems & 3 \\
\hline Library & 8 & Fire Station Systems & 3 \\
\hline Library Systems & 8 & Tracking System & 2 \\
\hline Backup Software & 7 & & \\
\hline
\end{tabular}

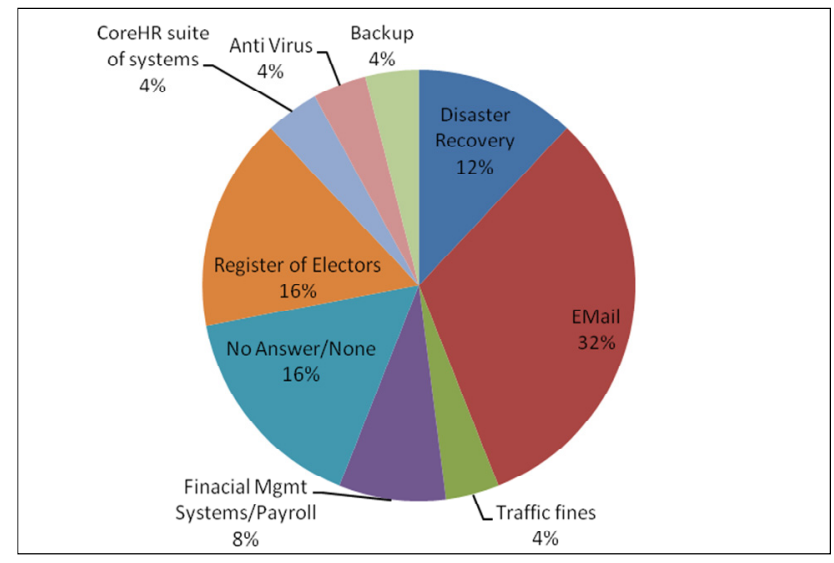

Fig. 2. Single most useful application as rated by users

It was noted in the literature review that strong governance is seen as critical to effective implementation of shared services. This was strongly supported by respondents (see table 3).

When asked about the problems and barriers to adoption, the barriers identified coincided with the literature, but none was strongly supported. The strongest concern was loss of local control and there was no clear view on technical issues or legacy systems. 
Table 3. Importance of governance (rated from $5=$ strongly agree to $1=$ strongly disagree)

\begin{tabular}{|l|l|l|}
\hline Question & Statement & $\begin{array}{l}\text { Mean } \\
\text { Score }\end{array}$ \\
\hline 12 & $\begin{array}{l}\text { For the successful implementation there must be strong } \\
\text { IT governance. }\end{array}$ & 4.48 \\
\hline 18 & $\begin{array}{l}\text { Central leadership and drive is a critical factor for the } \\
\text { adoption of shared services }\end{array}$ & 4.40 \\
\hline 16 & $\begin{array}{l}\text { Standardisation of platforms and systems is a key bene- } \\
\text { fit of shared services }\end{array}$ & 4.35 \\
\hline
\end{tabular}

Table 4. Barriers to adoption (rated from $5=$ strongly agree to $1=$ strongly disagree)

\begin{tabular}{|l|l|l|}
\hline Question & Statement & $\begin{array}{l}\text { Mean } \\
\text { Score }\end{array}$ \\
\hline 17 & $\begin{array}{l}\text { Loss of local control is a concern when adopting shared } \\
\text { services }\end{array}$ & 3.35 \\
\hline 13 & $\begin{array}{l}\text { Frustration at the user-level and alienation between Shared } \\
\text { Service Centres and local authorities is a problem }\end{array}$ & 3.57 \\
\hline 19 & $\begin{array}{l}\text { Loss of local technical skill and knowledge is a concern } \\
\text { when adopting shared services }\end{array}$ & 3.35 \\
\hline 14 & $\begin{array}{l}\text { Budget constraints have an impact on whether ICT shared } \\
\text { services are adopted }\end{array}$ & 3.30 \\
\hline 15 & $\begin{array}{l}\text { Concerns about cost control are a barrier to the adoption of } \\
\text { shared service }\end{array}$ & 3.22 \\
\hline 11 & $\begin{array}{l}\text { Lack of progress is due to technical issues such as problems } \\
\text { with legacy systems and underdeveloped infrastructure }\end{array}$ & 2.96 \\
\hline
\end{tabular}

A number of interesting comments emerged from the free form question including the variety of views on the reasons for lack of take-up. Over 60 percent of respondents said that they would prefer a regional to a national shared services centre, but half said that their own LA would not be willing to act as a regional host. There was a diversity of view on who should take the leadership role in promoting shared services.

In the free comment part of the questionnaire the dominant barriers to take up were identified as culture, governance, affordability and lack of trust. This suggests that the lack of success in shared services in LAs in Ireland is due to a failure of leadership and management and has little to do with the technology. Problems such as lack of resources or shortages of technical skills were not considered significant. Poor business cases and lack of leadership emerged as the common themes as did failure to standardise business processes. Many respondents felt that trying to implement shared services without making key procedural changes first was a core problem. What emerges from the survey is reasonable support for findings in the literature, but also a wide diversity of views on every aspect of shared services from barriers to adoption to solutions to the problem of low take-up. It might be an exaggeration to describe this as a wicked problem [5], but it is certainly a complex one. 


\subsection{Interviews}

A somewhat different perspective emerged from the interview. The county managers had a different worldview, placing the questions in a broader context by discussing a wide range of shared services beyond ICT though they too agreed that the pattern of adoption was patchy. There are places in Irish local government where there is extensive cooperation between local authorities and other areas where silos persist.

One of the questions that arose during the interviews was how ICT can learn from the success stories in other shared services within local authorities? Amongst the key things that emerged was that strong SLAs are critical; so-called 'gentleman's agreements' generally do not work. There need to be proper legal contracts in place. There also needs to be strong central management with clear roles and responsibilities. Agreed and acceptable allocation of costs and charges is important. Unpleasant surprises arising from cost increases need to be avoided as these undermine confidence. Political leadership is essential. The role of central government in promoting shared services is part of this. In contrast to the importance placed by the HISs on standarising business processes, the county managers emphasised that there are regional variations in business processes which must be addressed. Confirming what is reported in the literature, the managers were clear that for shared services to succeed there should be no perception of loss of local control. It was also felt that data sharing was perhaps more important than process sharing. There was a divergence of views on leadership. Everybody agreed that there is a need for strong leadership and that there is currently a lack of leadership, but there is no unanimity on where that leadership should come from.

\section{$5 \quad$ Reflections}

While it might seem self evident that there must be considerable scope of shared services in ICT in Irish LAs, there is no consensus on what services should be shared and a good deal of ambivalence about willingness to avail of such services were they to be offered. There is a conflict between the view that says everything needs to be standardised and the view that there are local variations which need to be taken into account despite the existence of national policies on many of these matters. A good example of the problem of local variation was provided by Dunn [10] when she examined the criteria for local authority public housing lists in all 34 local authorities in Ireland. She found almost no consistency in the rules that were applied for prioritising waiting lists. There is a need for more research into the extent of local variation in services.

The research confirms the conjecture underlying question two that take-up is low. Overall only 31 percent of the potential range of offerings has been adopted. The barriers to adoption were the subject of the third question. Those identified in this research coincide largely with those reported by other researchers. Almost nobody identified technology as a barrier. The barriers are classically those of management and organisational pathologies. The final question asked what might be done to increase the adoption rate? Historically it would appear that the very structure and role of old LGCSB and its unclear relationship with local authorities in general and the 
larger LAs in particular was a problem from the start. The absence of proper SLAs and difficulties with the pricing mechanism have aggravated the problem. Technology difficulties, particularly with a centrally developed human resource management system, have not helped. As in many similar situations, while the technology gets blamed, it is only a proxy for other, more fundamental, problems. Finally, part of the problem lies in the current structure of the LGMA where decisions related to shared services are made by an IT committee comprised of county managers and HISs. It may be unrealistic to expect a group so composed to make decisions which would effectively transfer resources and power from their own organisations to a central body even if, in theory, they own that body [2].

The absence of strong and clear leadership has allowed a situation to develop which, if not anarchic, is diverse, uncoordinated and inefficient. The main hopes on the horizon may be the recent reorganisation of the LGMA and the emergence of cloud computing. Asked about cloud computing in the survey all respondents were positive and saw this as a promising development. Nonetheless the cloud too has the potential to become yet another technological patch which will not work unless more fundamental procedural, managerial, organisational and structural problems are addressed. That it can be done is not in question. It is also worthwhile noting there have been other attempts at developing shared services in Ireland which have been successful. One notable case is the Institutes of Technology (of which there are 16) which have over the past five years implemented an effective shared service solution not dissimilar to the type of solution envisaged for the local authorities [3].

It may be that financial pressures will force local authorities into more take-up of shared services, but that will only happen if they are convinced that shared services are more cost-effective and that the price of those services will be consistent over time. A more radical solution to the problem would be to put in place a strong central authority with essentially central financial control of ICT budgets throughout the local authority sector. This would be extremely difficult to put into practice politically and could hardly be considered to be democratic, but it may be the only long term solution.

\section{References}

1. Kearney, A.T.: Success through shared services From back office functions to shared drivers (2003), http: //www.atkearney.com/main.taf?p=5,3,1,74 (retrieved January 19, 2008)

2. Bannister, F.: e-Government and Administrative Power: The one-stop-shop meets the turf war. Electronic Government: An International Journal 2(2), 160-176 (2005)

3. Bannister, F., Connolly, R.: Sense and Sensitivity: Power and shared services in public sector ICT. In: Hahamis, P. (ed.) Proceedings of the 8th European Conference on eGovernment, Academic Conferences International, Lausanne, Switzerland, July 10-11, pp. 51-62 (2008)

4. Bergeron, F.: Essential of Shared Services. John Wiley and Sons, Hoboken (2003)

5. Buchanon, R.: Wicked Problems in Design Thinking. Design Issues 8(2), 5-21 (1992) 
6. Corradini, F.E.A.: Shared Services Center for E-Government Policy. In: eGov-Interop 2005, Geneva, Switzerland (2005)

7. David, A.W.: Learning to share. The American City \& Country 120(3) (2005)

8. Dunn, R.: Local Authority Housing: A Review of the Assessment and Allocation System. MSc Dissertation, Institute of Public Administration, Dublin (2007) (unpublished)

9. Geoff, T.: Peace in our time. Supply Management 3(34) (1998)

10. Janssen, M.: Managing the development of shared service centers: stake-holder considerations. In: Proceedings of the 7th International Conference on Electronic Commerce. ACM, Xi'an (2005)

11. Janssen, M., Joha, A.: Issues in relationship management for obtaining the benefits of a shared service center. In: Proceedings of the 6th International Conference on Electronic Commerce. ACM, Delft (2004)

12. Janssen, M., Wagenaar, R.: An Analysis of a Shared Services Centre in EGovernment. In: Proceedings of the 37th Hawaii International Conference on System Sciences - 2004. IEEE Computer Society, Hawaii (2004)

13. Kagelmann: Shared Services al alternative Organisations form; am beispiel der Finanzfunktion in muknationionalen Konzern. PhD. thesis, Universitat Rostock, Wiesbaden, Germany, Deutscher Universtat-Verlag (2000)

14. Quinn, F.R.C., Kris, A.: Shared services, Mining for Corporate Gold. Pearson Education, Harlow (2000)

15. Marijn, J., Anton, J.: Emerging shared service organizations and the service-oriented enterprise. Strategic Outsourcing: an International Journal 1, 35 (2008)

16. McWilliams, B.S.: Have you considered insourcing? Across the Board 33, 31 (1996)

17. Mitchell, R.K., Agle, B.R., Wood, D.J.: Toward a Theory of Stake-holder Identification and Salience: Defining the Principle of How and What Really Counts. The Academy of Management Review 22(4), 853-886 (1997)

18. Moller, P.: Implementing Shared Services in Europe. Treasury Management International. No longer accessible on the web (1997)

19. Niehaves, B., Krause, A.: Shared service strategies in local government - a multiple case study exploration. Transforming Government: People, Process and Policy 4(3), 266-279 (2010)

20. Proservartner, UK unveils government shared services model (2011), http: / /www . proservartner.co.uk/uk-unveils-governmentshared-services-model/ (retrieved March 14, 2012)

21. Ren, Wagenaar, W.: Governance of shared service centers in public administration: dilemmas and trade-offs. In: Proceedings of the 8th International Conference on Electronic Commerce: The New e-commerce: Innovations for Conquering Current Barriers, Obstacles and Limitations to Conducting Successful Business on the Internet, ACM, Fredericton (2006)

22. Robert, C.: The shared services journey. CMA Management 80(29) (2006a)

23. Robert, C.: Service level agreements: a shared services cornerstone. CMA Management 80(27), 37 (2006b)

24. Ruggini, J.: Making Local Government More Workable through Shared Services. Government Finance Review 22, 30 (2006)

25. Smith, C., Henschel, E., Lefeber, R.: Consolidation And Shared Services. Government Finance Review 24, 14 (2008)

26. Tomkinson, R.: Shared services in local government: improving service delivery. Aldershot, Gower (2007) 
27. Ulbrich, F.: Introducing a Research Project on Shared Services in Govern-ment Agencies. Research Paper Presented at the 17th Scandinavian Academy of Management (NFF) Conference, Reykjavik, Iceland (2003),

http: / /www.hhs.se/NR/rdonlyres / 9A0E6BA8-EDFA-46D3-9792 0042F100305F/2453/cms_20030814_paper.pdf (retrieved March 18, 2008)

28. Ulbrich, F.: How Swedish Government Agencies Translate the Shared Services Idea. In: Lundesberg, M., Martensson, P., Mahring, M. (eds.) IT Business Performance, EFI Yearbook, Stockholm School of Economics, Stockholm, pp. 113-134 (2006)

29. Weill, P., Ross, J.: IT Governance: How Top Performers Manage IT Decision Rights for Results. Harvard Business School Press, Cambridge (2004) 